\title{
Why preantepenultimate stress in Latin requires an OT-account
}

\author{
Haike Jacobs
}

\section{Introduction}

The well-known Classical Latin stress rule (stress is on the penultimate syllable if heavy and otherwise on the antepenultimate syllable) has been well studied in metrical theory (Hayes (1995), Halle (1997), Prince and Smolensky (1993), Mester (1994), among others). There is one important fact, however, that, although well-known in the traditional literature (cf. Lindsay (1963) among others), has never received any attention in recent metrical theory. In Early Classical Latin (by the time of Plautus and Terence; third/second century BC) there was a systematic exception to the Classical (first century BC) stress rule. In words of exactly four syllables with the first three syllables light, main stress was on the initial syllable. Some examples are fácilius 'easy', fáciliter, 'easily', básilicus 'royal', múlierem 'woman', bálineum 'bath' and inopiam 'poverty'.

In this paper, we will stress the implications and theoretical importance for metrical theory of the facts mentioned above, and, we will show that the proposed analysis of Early Classical Latin provides a principled account of the typological intricacies of previous footextrametricality. Moreover, it will be argued that the facts of Early Classical Latin cannot be adequately described in a rule-based framework, but, instead, require an OT-account.

\section{The Constraint NoNFINALITY and Main Stress in Latin}

Prince and Smolensky (1993) have provided an OT-analysis of Classical Latin. Here we will concentrate on the constituent structure 
they derive and not go into the details of their analysis with respect to the various shortening processes (cf. Jacobs (2000a and 2000b). The constraints they assume are given in (1) and (2), of which those in (1) are supposed to be undominated. Main stress is indicated by underscoring.

(1) Constraints for the Form of Feet

$\mathrm{Lx} \approx \mathrm{Pr}: \quad$ A member of MCAT corresponds to a PrWD, a lexical item must be prosodically analyzed.

FTBIN: $\quad$ Feet are binary at some level of analysis $(m, \sigma)$

RHTYPE (T): The rhythm type is trochaic, that is feet are trochees.

RHHRM: Rhythmic harmony or $*(\mathrm{HL})$ : an uneven trochee is forbidden.

(2) Constraints for Position/Parsing

$\operatorname{NonFinality~}(\underline{\mathrm{F}}, \underline{\sigma}) » \operatorname{EDgEMOST}(\underline{\sigma}, \mathrm{R})$

No head of PrWd is final in PrWd (both foot and head syllable) dominates the constraint that forces the stressed syllable to be located at the right word edge.

Motivation for the ranking:

$(\underline{\mathrm{LL}}) \mathrm{L}$ is better than $\mathrm{L}(\underline{\mathrm{LL}})$

$\operatorname{EdgEMOST}(\underline{\sigma}, \mathrm{R}) \gg$ PARSE- $\sigma$

Parse syllables into feet is dominated by stressed syllable location.

Motivation for the ranking: $\quad \mathrm{L}(\underline{\mathrm{LL}}) \mathrm{L}$ is better than $(\underline{\mathrm{LL}})(\mathrm{LL})$

In order to clarify the various constraints we give in (3) a tableau for an input HLL, HLH and LLL. 
(3) Main Stress in Classical Latin

\begin{tabular}{|c|c|c|c|}
\hline (a) /HLL/ & NONFIN & EDGEMOST & PARSE- $\sigma$ \\
\hline$(1)^{1 \mathrm{~B}^{\mathrm{D}}}(\underline{\mathrm{H}})(\mathrm{LL})$ & & $\sigma \sigma$ & \\
\hline (2) $(\underline{\mathrm{HL}}) \mathrm{L}$ & & $\sigma \sigma$ & $* !$ \\
\hline (3) $(\mathrm{H})(\underline{\mathrm{LL}})$ & $* !$ & $\sigma$ & \\
\hline (b) /HLH/ & NONFIN & EDGEMOST & PARSE- $\sigma$ \\
\hline$(1)(\mathrm{H}) \mathrm{L}(\underline{\mathrm{H}})$ & $* !$ & & * \\
\hline (2) $(\underline{\mathrm{H}}) \mathrm{LH}$ & & $\sigma \sigma$ & $* * !$ \\
\hline (3) $(\underline{\mathrm{H}}) \mathrm{L}(\mathrm{H})$ & & $\sigma \sigma$ & $* !$ \\
\hline$(4)(\underline{H})(\mathrm{LH})$ & & $\sigma \sigma$ & \\
\hline (c) $/ \mathrm{LLL} /$ & NONFIN & EDGEMOST & PARSE- $\sigma$ \\
\hline (1) $\mathrm{L}(\underline{\mathrm{LL}})$ & $* !$ & $\sigma$ & * \\
\hline$(2)(\underline{\mathrm{L}} \mathrm{L}) \mathrm{L}$ & & $\sigma \sigma$ & * \\
\hline
\end{tabular}

An input HLL (3a) is optimally parsed as $(\underline{H})(L L)$. The output candidate ( $\underline{\mathrm{HL}}) \mathrm{L}$ (a2) not only violates the undominated constraint *(HL), but also PARSE- $\sigma$. The output candidate $(\mathrm{H})(\underline{L} L)(\mathrm{a} 3)$ violates NONFINALITY, given that the foot with main stress is in final position. It is clear from the above examples that main stress will not always be on the final foot. Sometimes main stress is on the final foot as in $\mathrm{L}(\underline{\mathrm{L}} \mathrm{L}) \mathrm{L}$, $(\underline{\mathrm{LL}}) \mathrm{L},(\underline{\mathrm{H}}) \mathrm{L}$ or $(\underline{\mathrm{LL}})$ cases, but other times on the prefinal foot: as in $(\underline{\mathrm{H}})(\mathrm{LL})$ and $((\underline{\mathrm{H}})(\mathrm{LH})$ cases. In this respect, the analysis of Latin main stress is clearly different from an approach along the lines of Hayes' (1995) End Rule Final/Initial. The constraints responsible for main stress Align HEAD-Foot, R, PRWD, R (H/R) and (Align HEAD-FoOT, L, PRWD, L (H/L) (the OT translation of the End Rule cf. Kager (1999)), which demand that the head-foot be final or initial, must be dominated by NONFINALITY. 
Let us next consider an alternative analysis of Classical Latin. The constraints assumed are given in (4). We will leave the constraints in (1) unaltered, except crucially for the constraint banning the uneven trochee: *(HL) (cf. Prince and Smolensky, 1993). Prince and Smolensky assume that this constraint is universally undominated. We will assume that this constraint can, in fact, be dominated by other constraint, and that, in Latin, it is dominated by PARSE- $\sigma$. Also, instead of the constraint EDGEMOST, we will use ALIGN-constraints to account for the location of main stress.

Undominated constraints:

$\mathrm{LX} \approx \operatorname{Pr}, \mathrm{FTBIN}, \mathrm{RHTYPE}(\mathrm{T})$

Modified constraints:

NONFINALITY: A foot may not be final

ALIGN (PRWD,R, FT,R)

Align (HEAD-FoOT, R, PRWD, R) (H/R)

Ranked constraints:

NONFIN » W/R » $\mathrm{H} / \mathrm{R}$ » PARSE- $\sigma$ » $\mathrm{QS}$ » *(HL)

The constraints in (4) (and with NONFINALITY doubly simplified) will always yield main stress on the final foot. A foot will never be final except if forced by the higher ranked constraint: FTBIN. This accounts for monosyllabic words. This also means that $\mathrm{HH}$ will be optimally parsed as $(\underline{\mathrm{H}}) \mathrm{H}$ and not as $(\underline{\mathrm{H}})(\mathrm{H})$, given that the parsing of the final syllable results in a violation of the higher-ranked modified NONFINALITY constraint. A bisyllabic input $\mathrm{LH}$ will still be $(\underline{\mathrm{LH}})$ and not $(\underline{\mathrm{L}}) \mathrm{H}$ which violates FTBIN. Although both $\mathrm{L}(\underline{\mathrm{H}})$ and $(\underline{\mathrm{L}} \mathrm{H})$ violate NonFInALITY, $(\underline{\mathrm{L}} \mathrm{H})$ will be evaluated better. Although it does violate QS it avoids a violation of PARSE- $\sigma$ ranked above QS, the constraint responsible for quantity-sensitivity, which demands that heavy syllables are stressed. 
Words ending in HLL will optimally be parsed as (HL)L, because (H)(LL) (the optimal candidate of (3)) violates NONFINALITY and because $(\mathrm{H}) \mathrm{LL}$ entails one more violation of PARSE- $\sigma$ ranked above *(HL). Words ending in HLH will be optimal if (HL)H. The joint effect of these modifications (NoNFINALITY simplified (neither reference to main foot nor to stressed syllable) and $*(\mathrm{HL})$ dominated by PARSE- $\sigma$ ) results in main stress being uniformely on the last foot. In (5) this is illustrated for the crucial HLL and HLH cases.

(5) Main Stress in Classical Latin

\begin{tabular}{||l|l|l|l|l|l|l||}
\hline \hline$(\mathrm{a}) / \mathrm{HLL} /$ & NONFIN & W/R & H/R & PARSE- $\sigma$ & QS & $*(\mathrm{HL})$ \\
\hline$(\underline{\mathrm{H}})(\mathrm{LL})$ & $* !$ & & $\sigma \sigma$ & & & \\
\hline$(\underline{\mathrm{H}}) \mathrm{LL}$ & & $\sigma \sigma !$ & $\sigma \sigma$ & $* *$ & & \\
\hline$\sigma(\underline{\mathrm{HL}}) \mathrm{L}$ & & $\sigma$ & $\sigma$ & $*$ & & $*$ \\
\hline$(\mathrm{H})(\underline{\mathrm{LL}})$ & $* !$ & & & & & \\
\hline$(\mathrm{b}) / \mathrm{HLH} /$ & NON-FIN & $\mathrm{W} / \mathrm{R}$ & $\mathrm{H} / \mathrm{R}$ & PARSE- $\sigma$ & $\mathrm{QS}$ & $*(\mathrm{HL})$ \\
\hline$(\underline{\mathrm{H}}) \mathrm{L}(\mathrm{H})$ & $* !$ & & $\sigma \sigma$ & $*$ & & \\
\hline$(\underline{\mathrm{H}}) \mathrm{LH}$ & & $\sigma \sigma !$ & $\sigma \sigma$ & $* *$ & $*$ & \\
\hline$(\underline{\mathrm{H}})(\mathrm{LH})$ & $* !$ & & $\sigma \sigma$ & & $*$ & \\
\hline$\sigma(\underline{\mathrm{HL}}) \mathrm{H}$ & & $\sigma$ & $\sigma$ & $*$ & $*$ & $*$ \\
\hline
\end{tabular}

It goes without saying that the proposed analysis has considerable consequences for the analysis of both shortening and syncope in Latin. We refer for a more detailed account to Jacobs (2000a and 2000b). In the next section we will concentrate on the constraint NONFINALITY and show why the proposed modification is necessary on typological grounds. It will be demonstrated that the constraint NoNFINALITY as proposed by Prince and Smolensky leads to the prediction of quaternary stress, and, that therefore, a modification of the constraint is independently required. 


\section{NONFINALITY $(\underline{F}, \underline{\sigma})$ and quaternary stress systems}

It is a well-known fact that quaternary systems do not occur (cf. Hayes (1995) and van der Hulst (1999). What may occur in a language, though, is a quaternary pattern. That is, as in Early Classical Latin mentioned above, sometimes stress can fall on the pre-antepenultimate, the fourth, syllable from the end, but not systematically in all words.

In Prince and Smolensky's analysis of Latin in (1)-(3) above we saw that a ranking NonFinALITY $(\underline{F}, \underline{\sigma})$ ) EDGEMOST » PARSE- $\sigma$ resulted in preferring $\mathrm{L}(\underline{\mathrm{LL}}) \mathrm{L}$ to $(\underline{\mathrm{LL}})(\mathrm{LL})$ and in preferring $(\underline{\mathrm{H}})(\mathrm{LL})$ to $(\mathrm{H})(\underline{\mathrm{LL}})$.

In (6) we have presented the same constraints, but in a different order. We have ranked PARSE- $\sigma$ above NONFInALITY $(\underline{F}, \underline{\sigma})$, which has the consequence of deriving a stress system where main stress is systematically on the fourth syllable from the right-edge. This is illustrated for words containing four, five and six light syllables. For ease of exposition, we have abstracted away from quantity-sensitivity.

(6) A Systematic Quaternary Stress System

\begin{tabular}{||c|c|c|c|c||}
\hline a. $/ \sigma \sigma \sigma \sigma /$ & PARSE- $\sigma$ & $\operatorname{NONFIN~}(\underline{F}, \underline{\sigma})$ & W/R & H/R \\
\hline$\sigma(\underline{\sigma} \sigma)(\sigma \sigma)$ & & & & $\sigma \sigma$ \\
\hline$\sigma(\underline{\sigma} \sigma) \sigma$ & $* ! *$ & & $\sigma$ & $\sigma$ \\
\hline$(\underline{\sigma} \sigma) \sigma \sigma$ & $* ! *$ & & $\sigma \sigma$ & $\sigma \sigma$ \\
\hline$(\sigma \sigma)(\underline{\sigma} \sigma)$ & & $* !$ & & \\
\hline
\end{tabular}

\begin{tabular}{||c|c|c|c|c||}
\hline b. $/ \sigma \sigma \sigma \sigma \sigma /$ & PARSE- $\sigma$ & $\operatorname{NONFIN(} \underline{\mathrm{F}} \underline{\sigma})$ & $\mathrm{W} / \mathrm{R}$ & $\mathrm{H} / \mathrm{R}$ \\
\hline$\sigma(\underline{\sigma} \sigma)(\sigma \sigma)$ & $*$ & & & $\sigma \sigma$ \\
\hline$(\underline{\sigma} \sigma) \sigma(\sigma \sigma)$ & $*$ & & & $\sigma \sigma \sigma !$ \\
\hline$\sigma(\sigma \sigma)(\underline{\sigma} \sigma)$ & $*$ & $* !$ & & \\
\hline$(\sigma \sigma)(\underline{\sigma} \sigma) \sigma$ & $*$ & & $\sigma !$ & $\sigma$ \\
\hline
\end{tabular}




\begin{tabular}{||c|c|c|c|c||}
\hline c. $/ \sigma \sigma \sigma \sigma \sigma \sigma /$ & PARSE- $\sigma$ & $\operatorname{NONFIN}(\underline{F}, \underline{\sigma})$ & W/R & H/R \\
\hline$\sigma(\sigma \sigma)(\underline{\sigma} \sigma)(\sigma \sigma)$ & & & & $\sigma \sigma$ \\
\hline$(\sigma \sigma)(\sigma \sigma)(\underline{\sigma} \sigma)$ & & $* !$ & & \\
\hline$\sigma(\sigma \sigma)(\underline{\sigma} \sigma) \sigma$ & $* ! *$ & & $\sigma$ & $\sigma$ \\
\hline
\end{tabular}

It is obvious from (6) that the constraint NonFINALITY $(\underline{F}, \underline{\sigma})$ makes the unwanted prediction of the possible existence of quaternary stress systems.

Before proceeding our discussion, we have illustrated in tableau (7) that the modified constraint NONFINALITY, as in (4), which we used for Latin, does not lead to the same prediction, but correctly excludes systematic quaternarity.

(7) Systematic Quaternary Stress Excluded

\begin{tabular}{||c|c|c|c|c||}
\hline a. $/ \sigma \sigma \sigma \sigma /$ & PARSE- $\sigma$ & $\operatorname{NONFIN~}(\mathrm{F})$ & W/R & H/R \\
\hline$(\underline{\sigma} \sigma)(\sigma \sigma)$ & & $*$ & & $\sigma ! \sigma$ \\
\hline$\sigma(\underline{\sigma} \sigma) \sigma$ & $* ! *$ & & $\sigma$ & $\sigma$ \\
\hline$(\underline{\sigma} \sigma) \sigma \sigma$ & $* ! *$ & & $\sigma \sigma$ & $\sigma \sigma$ \\
\hline$\sigma^{*}(\sigma \sigma)(\underline{\sigma} \sigma)$ & & $*$ & & \\
\hline
\end{tabular}

\begin{tabular}{||c|c|c|c|c||}
\hline b. $/ \sigma \sigma \sigma \sigma \sigma /$ & PARSE- $\sigma$ & NONFIN $(\mathrm{F})$ & W/R & H/R \\
\hline$\sigma(\underline{\sigma} \sigma)(\sigma \sigma)$ & $*$ & $* !$ & & $\sigma \sigma$ \\
\hline$(\sigma \sigma)(\underline{\sigma} \sigma) \sigma$ & $*$ & & $\sigma$ & $\sigma$ \\
\hline$(\underline{\sigma} \sigma) \sigma(\sigma \sigma)$ & $*$ & $* !$ & & $\sigma \sigma \sigma$ \\
\hline$\sigma(\sigma \sigma)(\underline{\sigma} \sigma)$ & $*$ & $* !$ & & \\
\hline
\end{tabular}




\begin{tabular}{||c|c|c|c|c||}
\hline c. $/ \sigma \sigma \sigma \sigma \sigma \sigma /$ & PARSE- $\sigma$ & NONFIN $(F)$ & W/R & H/R \\
\hline$(\sigma \sigma)(\underline{\sigma} \sigma)(\sigma \sigma)$ & & $*$ & & $\sigma ! \sigma$ \\
\hline$(\sigma \sigma)(\sigma \sigma)(\underline{\sigma} \sigma)$ & & $*$ & & \\
\hline$\sigma(\sigma \sigma)(\underline{\sigma} \sigma) \sigma$ & $* ! *$ & & $\sigma$ & \\
\hline
\end{tabular}

In this section, we have argued that a modification of the constraint NONFINALITY is needed in order to exclude the existence of quaternary stress systems. However, we still have to account for existing quaternary patterns in a language, such as Early Classical Latin. In the next section, we will first discuss how in rule-based theory, more specifically extrametricality theory, the concept of foot-extrametricality permits to account for quaternary patterns in a language.

\section{Foot and syllable extrametricality}

Hayes (1995) has proposed to use Foot-extrametricality for a number of languages. The use of Foot-extrametricality can be divided into two types: one, to which we will refer as Free Foot-Extrametricality and the other, to which we will refer as Clash Foot-Extrametricality. Clash Foot-Extrametricality is a restricted use of extrametricality. First, the word is parsed into feet and then the last foot is made extrametrical, but only if in clash with a preceding foot. Turkish non-final stress in loanwords and toponyms (cf. Hayes, 1995:262, based on Sezer (1983)) is analyzed in two possible ways, one of which invokes Clash FootExtrametricality.

First, (i) moraic trochees are constructed from right-to-left, then, (ii) the final foot is made extrametrical if in clash with a preceding foot. Finally, (iii) the application of the End Rule Final produces main stress on the final foot. Sample derivations are given in (8). 
(8) Turkish Foot Extrametricality in Clash

$\begin{array}{lllll}\text { a. lo } & \text { kán } & \text { ta } \\ \text { L } & \text { H } & \text { L } & \end{array}$

(i) (x)

(ii) not applicable

(iii) $(\mathrm{x})$

b. an ták ya Place Name

$\mathrm{H} \quad \mathrm{H} \quad \mathrm{L}$

(i) (x) (x)

(ii) not applicable

(iii) $(x) \quad(x)$

$(\mathrm{x} \quad)$

c. ka ná pe 'couch'

L L L

(i) $\quad\left(\begin{array}{ll}x & .\end{array}\right)$

(ii) not applicable

(iii) $\left(\begin{array}{ll}(\mathrm{x} & .) \\ \mathbf{x} & )\end{array}\right.$

d. án ka ra Place Name

H L L

(i) $\quad(\mathrm{x}) \quad(\mathrm{x} \quad$.

(ii) $(\mathrm{x}) \quad<\left(\begin{array}{ll}\mathrm{x} & \text {.) }\end{array}>\right.$

(iii) $(\mathrm{x})<\left(\begin{array}{ll}\mathrm{x} & \text {.) })>\end{array}\right.$

(x)

Although the final foot in (8b) is in clash with the preceding foot, the final foot is not peripheral and, hence, not subject to extrametricality.

Only in (8d) the final foot is both in clash with the preceding foot and peripheral, and, hence, subject to foot-extrametricality. In the other 
cases in (8), there is no clash and, hence, no foot-extrametricality (cf. Hayes (1995) and Gussenhoven and Jacobs (1998) for more discussion).

In cases of Free Foot-Extrametricality the final foot is made extrametrical irrespective of clash considerations. A typical example is Palestinian Arabic, where preantepenultimate stress occurs in words ending in four light syllables. Hayes (1995: 126/127) assumes, final consonant extrametricality, left-to-right moraic trochees, final foot extrametricality and End Rule Final. Some examples are given in (9).

(9) Palestinian Arabic Foot Extrametricality

\begin{tabular}{|c|c|c|c|c|c|c|}
\hline \multirow[t]{3}{*}{ a. } & ká & ta & bu & & & \multirow[t]{4}{*}{ 'they wrote' } \\
\hline & $\mathrm{L}$ & $\mathrm{L}$ & $\mathrm{L}$ & & & \\
\hline & (x & .) & & & & \\
\hline & $(\mathrm{x}$ & & ) & & & \\
\hline \multirow[t]{4}{*}{ b. } & sá & ja & ra & \multicolumn{2}{|l|}{$\mathrm{tu}<\mathrm{n}>$} & \multirow[t]{4}{*}{ 'a tree' } \\
\hline & $\mathrm{L}$ & $\mathrm{L}$ & $\mathrm{L}$ & $\mathrm{L}$ & & \\
\hline & $(\mathrm{x}$ & )$. & $<(\mathrm{x}$ & .)> & & \\
\hline & (x & & & ) & & \\
\hline \multirow[t]{4}{*}{ c. } & sa & ja & rá & tu & hu & \multirow[t]{2}{*}{ 'his tree (nom.)' } \\
\hline & $\mathrm{L}$ & $\mathrm{L}$ & $\mathrm{L}$ & $\mathrm{L}$ & $\mathrm{L}$ & \\
\hline & (x & )$. & $(\mathrm{x}$ & )$. & & \\
\hline & ( & & $\mathrm{X}$ & & ) & \\
\hline
\end{tabular}

The final foot in (9a) and (9c) is not peripheral and cannot be made extrametrical due to the Peripherality Condition. In (9b) the last syllable is treated as light, due to the prior application of a rule of consonant-extrametricality (cf. Hayes, 1995: 129). After making the final foot extrametrical, as in (9b), End Rule Final will promote the first foot to main stress status.

Hayes (1995) reports no cases of syllabic trochees with Free FootExtrametricality, which would result in systematic quaternarity. Now, 
quite strikingly, cases of left-ward footing (feet are assigned from rightto-left) plus Free Foot-Extrametricality are rare, if existant at all. There is one example given in Hayes (1995), Hindi, to which we will return below. All the examples of Free Foot-Extrametricality occur in rightward (feet are assigned from left-to-right) iambic or moraic trochee stress systems. The languages which are given in Hayes (1995) are: Palestinian Arabic, Munsee, Unami, Cayuga, Radio Cairene Arabic, Cyrenaican Bedouin Arabic, Negev Bedouin Arabic and Eastern Ojibwa (cf. Hayes (1995) for a more detailed account).

This directional asymmetry in Free Foot-Extrametricality is unexplained in a derivational theory, but makes perfect sense in OT, but only if NONFINALITY is indeed modified as we have proposed above for Latin. That is, the modification of NONFINALITY, as proposed here, according to which any foot in final position is disallowed, has the effect that parsing of syllables into feet will stop exactly two light syllables from the word end if footing is rightward. In leftward parsing NONFINALITY can be minimally satisfied by skipping just one syllable. Minimal violation is enforced by PARSE- $\sigma$. Hence, preantepenultimate stress is expected if the four last syllables of a word are light in rightward systems, but not in left-ward systems.

Let us now consider Hindi stress. In Hindi, we do find cases of preantepenultimate stress due to Free Foot-Extrametricality. Moraic trochees are constructed going from right to left. The final foot is made extrametrical and main stress is accounted for by the End Rule Right. Hayes (1995:165) notes that his analysis predicts the preantepenultimate maximum to occur only in cases with two disyllabic feet, which, by the definition of the moraic trochee, implies that the four last syllables are light. An example is ánumati 'approval' illustrated in (10).

(10) Hindi Pre-antepenultimate Stress

$$
\begin{aligned}
& (\mathrm{x}) \\
& \left(\begin{array}{ll}
x & .
\end{array}\right)<\left(\begin{array}{ll}
x & .
\end{array}\right)> \\
& \text { á nu ma ti }
\end{aligned}
$$

Such a quaternary pattern can arise by the ranking given in (11). 
(11) A Quaternary Pattern

\begin{tabular}{||c|c|c|c|c|c||}
\hline$/ \sigma \sigma \sigma /$ & NON-FIN & W/L & W/R & H/R & PARSE- $\sigma$ \\
\hline$\sigma(\underline{\sigma} \sigma) \sigma$ & & & $\sigma$ & $\sigma$ & $*$ \\
\hline$\sigma(\underline{\sigma} \sigma)$ & $* !$ & $\sigma$ & & & $*$ \\
\hline$/ \sigma \sigma \sigma \sigma /$ & NON-FIN & W/L & W/R & H/R & PARSE- $\sigma$ \\
\hline$\sigma(\underline{\sigma} \sigma) \sigma$ & & $\sigma !$ & $\sigma$ & $\sigma$ & $* *$ \\
\hline$(\underline{\sigma} \sigma)(\sigma \sigma)$ & $* !$ & & & $\sigma \sigma$ & \\
\hline$\sigma(\underline{\sigma} \sigma) \sigma \sigma$ & & & $\sigma \sigma$ & $\sigma \sigma$ & $* *$ \\
\hline$/ \sigma \sigma \sigma \sigma \sigma /$ & NoN-FIN & W/L & W/R & H/R & PARSE- $\sigma$ \\
\hline$\sigma(\sigma \sigma)(\underline{\sigma} \sigma) \sigma$ & & & $\sigma$ & $\sigma$ & $*$ \\
\hline$\sigma(\underline{\sigma \sigma})(\sigma \sigma)$ & $* !$ & $\sigma$ & & $\sigma \sigma$ & $*$ \\
\hline$(\sigma \sigma) \sigma(\underline{\sigma} \sigma)$ & $* !$ & & & & $*$ \\
\hline$/ \sigma \sigma \sigma \sigma \sigma \sigma /$ & NON-FIN & W/L & W/R & H/R & PARSE- $\sigma$ \\
\hline$\sigma(\sigma \sigma) \sigma(\sigma \sigma) \sigma$ & & & $\sigma$ & $\sigma$ & $* *$ \\
\hline$\sigma(\sigma \sigma)(\underline{\sigma} \sigma) \sigma$ & & $\sigma !$ & $\sigma$ & $\sigma$ & $* *$ \\
\hline$(\sigma \sigma)(\underline{\sigma} \sigma)(\sigma \sigma)$ & $* !$ & & & $\sigma \sigma$ & \\
\hline \hline
\end{tabular}

In (11) we have, for clarity's sake, abstracted away from quantitysensitivity. The pattern that emerges from (11) is antepenultimate stress in longer words, but pre-antepenultimate stress being restricted to words of exactly four light syllables.

There are two important differences, however, between the analysis in (10) and (11). First, Hayes' analysis predicts that in a pentasyllabic word with the four last syllables light, main stress will also be on the fourth syllable from the word edge. Again, moraic trochees are constructed from right-to-left and the final foot is made extrametrical. This is illustrated in (12). 
(12) Pre-antepenultimate Stress in Longer Words as Well

$\begin{array}{ccccc} & \mathrm{x} & & & \\ & & & & \\ & (\mathrm{x} & .) & <(\mathrm{x} & .)> \\ \mathrm{L} & \mathrm{L} & \mathrm{L} & \mathrm{L} & \mathrm{L}\end{array}$

The analysis in (11), on the other hand, produces preantepenultimate stress only in tetrasyllabic words, but not in pentasyllabic ones. I have found no examples for Hindi in order to evaluate either analysis. In Early Classical Latin, however, which seems to work exactly like Hindi, only tetrasyllabic words show preantepenultimate stress, but not pentasyllabic ones.

Second, the analysis in (11) produces, in cases of words of four syllables, only one stress: on the first syllable and no secondary stress on the prefinal syllable. Hayes' analysis (cf. 10) predicts a secondary stress on the prefinal syllable in these words. Gupta (1987) notes explicitly that ánumàti is ill-formed in Hindi. Let us next turn to Early Classical Latin.

\section{Early Classical Latin}

In Early Classical Latin (Plautus 244-184 BC) preantepenultimate stress occurred only in quadrisyllabic words with the first three syllables light, but where the final syllable may be either light or heavy. Some examples are fácilius 'easy', fáciliter, 'easily', básilicus 'royal', múlierem 'woman' and bálineum 'bath'. Pentasyllabic words obey the antepenultimate maximum, such as, maleficium 'crime' or domicílium 'house' (cf Allen (1973, Fraenkel (1928), Thierfelder (1928) and Lindsay (1963) among others).

There are two good arguments supporting the traditional scholars' view of initial stress in these cases.

First, in the comedies of Plautus and Terence there was a strong tendency to harmonize verse ictus (the strong position in the verse foot) and word accent, and as Lindsay (1963: 158) puts it: "the metrical treatment of [these words] in the plays of Plautus and Terence, indicate 
that the pronunciation of such words in their time laid the accent on the first, and not on the second syllable. [...] the incidence of the metrical ictus in all other types of words points to the prevalence of the Paenultima Law for all words, except for these quadrisyllables with the first three syllables short."

Second, in some of these quadrisyllabic words it is exactly the syllable which under the Classical stress rule would have had the main stress, that is syncopated, such as, for instance, bálineum $>$ bálneum.

Finally, it is important to mention that there seems to be no morphological reason whatsoever supporting initial stress in precisely these cases. This is clear when one compares lábor fácilior 'more easy work; nom.sg.' and labórem faciliórem 'more easy work; acc. sg.' or básilicus 'royal; nom.sg.' basilicórum 'royal; gen.pl.' .

For Early Classical Latin, there is no direct way in which footextrametricality and a moraic trochee can reach the preantepenultimate syllable in quadrisyllabic words with a final heavy syllable, given that the final heavy syllable will form a foot on its own (viz. $L(\underline{L} L)<(H)>$ ). If, prior to foot-extrametricality, the last consonant is made extrametrical, which has the effect of making the final syllable light, one could in principle stress the initial syllable in these cases (viz. (LL) $<(\mathrm{LL})><-$ $\mathrm{C}>$ ). Notice that in these cases the final consonant must be supposed to be part of the syllable, in order to escape unallowed 'chained' or 'embedded' extrametricality, which is excluded by Hayes (1995:107) on principled grounds.

Moreover, given the fact that the use of both final consonant- and final foot-extrametricality has to be restricted to words of four syllables with the initial three syllables light, because in all other words the classical three-syllable window is respected, makes the analysis, if acceptable at all, completely ad-hoc.

A ranking such as the one in (11) above straightforwardly derives Plautinian Latin as shown in (13). 
(13) Preantepenultimate Stress in Early Classical Latin

\begin{tabular}{||c|c|c|c|c||}
\hline $\begin{array}{c}\text { L L L H } \\
\text { ba-li-ne-um }\end{array}$ & NoNFIN & W/L & W/R & PARSE- $\sigma$ \\
\hline$(\underline{L}$ L) L (H) & $* !$ & & & $*$ \\
\hline L $(\underline{L}$ L) H & & $\sigma !$ & $\sigma$ & $* *$ \\
\hline$(\underline{L} \mathrm{~L})(\mathrm{L} \mathrm{H})$ & $* !$ & & & \\
\hline$(\underline{\mathrm{L}} \mathrm{L}) \mathrm{L} H$ & & & $\sigma \sigma$ & $* *$ \\
\hline
\end{tabular}

In (14), we show for a pentasyllabic word, such as, for instance, maleficium 'crime' or domicilium 'house', that in all other cases the three-syllable window is respected.

(14) Pentasyllabic Words Have Antepenultimate Stress

\begin{tabular}{|c|c|c|c|c|}
\hline $\begin{array}{l}\text { L L L L H } \\
\text { ma-le-fi-ci-um }\end{array}$ & NONFIN & $\mathrm{W} / \mathrm{L}$ & $\mathrm{W} / \mathrm{R}$ & PARSE- $\sigma$ \\
\hline$(\underline{\mathrm{L}} \mathrm{L})(\mathrm{L} \mathrm{L})(\mathrm{H})$ & $* !$ & & & \\
\hline $\mathrm{L}(\underline{\mathrm{L}} \mathrm{L}) \mathrm{L} H$ & & $\sigma !$ & $\sigma \sigma$ & $* * *$ \\
\hline $\mathrm{L}(\underline{\mathrm{L}} \mathrm{L})(\mathrm{L} \mathrm{H})$ & $* !$ & $\sigma$ & & * \\
\hline$\varpi(\mathrm{L} L)(\underline{\mathrm{L}} \mathrm{L}) \mathrm{H}$ & & & $\sigma$ & * \\
\hline
\end{tabular}

Now, Early Classical Latin differs with respect to the rankings of the constraints in only one aspect from Preclassical Latin.

In Preclassical Latin stress always was on the initial syllable (cf. Lindsay (1963) among others), a situation which can be accounted for by the ranking in (15). The constraint which demands that the Prosodic Word starts with a foot, W/L, dominates the constraint that demands that the Prosodic Word ends with a foot, W/R. Furthermore, in order to obtain initial instead of final stress, $\mathrm{H} / \mathrm{L}$ must dominate $\mathrm{H} / \mathrm{R}$. 
(15) Preclassical Latin Initial Stress

\begin{tabular}{||l|c|c|c|c|c|c||}
\hline$/ \sigma \sigma \sigma \sigma /$ & NONF & W/L & W/R & H/L & H/R & PARSE- $\sigma$ \\
\hline$\sigma(\underline{\sigma} \sigma) \sigma$ & & $\sigma !$ & $\sigma$ & $\sigma$ & $\sigma$ & $* *$ \\
\hline$(\underline{\sigma} \sigma) \sigma(\sigma)$ & $* !$ & & & & $\sigma \sigma$ & $*$ \\
\hline$(\underline{\sigma} \sigma)(\sigma \sigma)$ & $* !$ & & & & $\sigma \sigma$ & \\
\hline$\sigma(\underline{\sigma} \sigma) \sigma \sigma$ & & & $\sigma \sigma$ & & $\sigma \sigma$ & $* *$ \\
\hline$/ \sigma \sigma \sigma \sigma \sigma /$ & NONF & W/L & W/R & H/L & H/R & PARSE- $\sigma$ \\
\hline$\sigma(\underline{\sigma} \sigma)(\sigma \sigma) \sigma$ & & & $\sigma$ & & $\sigma \sigma \sigma$ & $*$ \\
\hline$\sigma(\underline{\sigma} \sigma)(\sigma \sigma)$ & $* !$ & $\sigma$ & & $\sigma$ & $\sigma \sigma$ & $*$ \\
\hline$\sigma \sigma(\underline{\sigma} \sigma) \sigma$ & & $\sigma ! \sigma$ & & $\sigma \sigma$ & $\sigma$ & $* * *$ \\
\hline$(\underline{\sigma} \sigma) \sigma \sigma \sigma$ & & & $\sigma \sigma ! \sigma$ & & $\sigma \sigma \sigma$ & $* * *$ \\
\hline
\end{tabular}

High-ranking W/L and H/L will always produce initial stress. Quantityinsensitivity (cf. fénestra) is achieved, although not indicated in (15), by ranking the QS-constraint below the Alignment-constraints.

The evolution from Preclassical to Plautinian or Early Classical Latin can now be described more precisely as a reranking of the constraints $H / L$ and $H / R$ as in (16).

(16) Preantepenultimate Stress in Quadrisyllabic Words Only

\begin{tabular}{|c|c|c|c|c|c|c|}
\hline $\begin{array}{l}\text { /LLLH/ } \\
\text { o-pi-tu-mus }\end{array}$ & NONF & $\mathrm{W} / \mathrm{L}$ & W/R & $\mathrm{H} / \mathrm{R}$ & $\mathrm{H} / \mathrm{L}$ & PARSE- $\sigma$ \\
\hline$(\underline{\mathrm{L}} \mathrm{L}) \mathrm{L}(\mathrm{H})$ & $* !$ & & & $\sigma \sigma$ & & * \\
\hline $\mathrm{L}(\underline{\mathrm{L}} \mathrm{L}) \mathrm{H}$ & & $\sigma !$ & $\sigma$ & $\sigma$ & $\sigma$ & $* *$ \\
\hline$(\underline{L} \mathrm{~L})(\mathrm{L} \mathrm{H})$ & $* !$ & & & $\sigma \sigma$ & & \\
\hline$(\underline{\mathrm{L}} \mathrm{L}) \mathrm{L} H$ & & & $\sigma \sigma$ & $\sigma \sigma$ & & $* *$ \\
\hline
\end{tabular}


Tableau (17) shows, in a more precise way than (14), the effect of this ranking for penta- and hexasyllabic words.

(17) Early Classical Stress: Antepenultimate Stress in Longer Words

\begin{tabular}{|c|c|c|c|c|c|c|}
\hline $\begin{array}{l}\text { a. } / \mathrm{L} \mathrm{L} \mathrm{L} \mathrm{L} \mathrm{\sigma /} \\
\text { o-pi-fi-ci-na }\end{array}$ & NONF & $\mathrm{W} / \mathrm{L}$ & $\mathrm{W} / \mathrm{R}$ & $\mathrm{H} / \mathrm{R}$ & $\mathrm{H} / \mathrm{L}$ & PARSE- $\sigma$ \\
\hline$(\underline{\mathrm{L}} \mathrm{L})(\mathrm{L} \mathrm{L}) \sigma$ & & & $\sigma$ & $\sigma \sigma ! \sigma$ & & \\
\hline 蛙 $(\mathrm{L} L)(\underline{\mathrm{L}} \mathrm{L}) \sigma$ & & & $\sigma$ & $\sigma$ & $\sigma \sigma$ & * \\
\hline $\mathrm{L}(\underline{\mathrm{L}} \mathrm{L})(\mathrm{L} \sigma)$ & $* !$ & $\sigma$ & & $\sigma \sigma$ & $\sigma$ & * \\
\hline$(\mathrm{L} L) \mathrm{L}(\underline{\mathrm{L}} \sigma)$ & $* !$ & & & & $\sigma \sigma \sigma$ & * \\
\hline $\begin{array}{l}\text { b. /L L L L L } \sigma / \\
\text { re-stu-pe-fa-ci-o }\end{array}$ & NONF & $\mathrm{W} / \mathrm{L}$ & $\mathrm{W} / \mathrm{R}$ & $H / R$ & $\mathrm{H} / \mathrm{L}$ & PARSE- $\sigma$ \\
\hline$(\mathrm{L} \mathrm{L}) \mathrm{L}(\underline{\mathrm{L}} \mathrm{L}) \sigma$ & & & $\sigma$ & $\sigma$ & $\sigma \sigma \sigma$ & $* *$ \\
\hline $\mathrm{L}(\mathrm{L} \mathrm{L})(\underline{\mathrm{L}} \mathrm{L}) \sigma$ & & $\sigma !$ & $\sigma$ & $\sigma$ & $\sigma \sigma \sigma$ & $* *$ \\
\hline$(\mathrm{L} \mathrm{L})(\underline{\mathrm{L}} \mathrm{L})(\mathrm{L} \mathrm{L})$ & $* !$ & & & $\sigma \sigma$ & $\sigma \sigma$ & \\
\hline
\end{tabular}

The change from Early Classical to Classical Latin can then simply be described as the reranking of the AL-PRWD constraints, which has the effect that preantepenultimate stress is no longer possible, as shown in (18).

(18) No Preantepenultimate Stress In Classical Latin

\begin{tabular}{|c|c|c|c|c|c|c|}
\hline L L L H & NONFIN & $\mathrm{W} / \mathrm{R}$ & $\mathrm{W} / \mathrm{L}$ & $\mathrm{H} / \mathrm{R}$ & $\mathrm{H} / \mathrm{L}$ & PARSE- $\sigma$ \\
\hline$(\underline{L} \mathrm{~L}) \mathrm{L}(\mathrm{H})$ & $* !$ & & & $\sigma \sigma$ & & * \\
\hline$(\underline{L} \mathrm{~L})(\mathrm{L} \mathrm{H})$ & $* !$ & & & $\sigma \sigma$ & & \\
\hline $\mathrm{L}(\underline{\mathrm{L}} \mathrm{L}) \mathrm{H}$ & & $\sigma$ & $\sigma$ & $\sigma$ & $\sigma$ & $* *$ \\
\hline$(\underline{L} \mathrm{~L}) \mathrm{L} \quad \mathrm{H}$ & & $\sigma \sigma !$ & & $\sigma \sigma$ & & $* *$ \\
\hline
\end{tabular}




\section{Why derivational analyses fail and why OT is required}

In section 4, it was argued that the directional asymmetry in Free FootExtrametricality (that is, the observation that it occurs only in systems with rightward footing, but never in systems with leftward footing) is left unexplained in a derivational theory, but receives a principled explanation in OT, but only if the constraint NONFINALITY is modified as we have proposed above for Latin main stress. The constraint NONFINALITY has the effect that parsing of syllables in feet will stop exactly two light syllables from the word end if footing is rightward (that is, from left-to-right) and in leftward parsing (from right-to-left) NONFINALITY is minimally satisfied by skipping just one syllable, forced by PARSE- $\sigma$. Hence, preantepenultimate stress is expected if the four last syllables of a word are light in right-ward systems, but not in left-ward systems.

In section 5, it was shown how the quaternary pattern of Early Classical Latin can be accounted for in OT. However, in derivational terms, footing in Latin is leftward and not rightward. Preantepenultimate stress is due to the ranking of PRWD-LEFT (W/L) above PRWD-RIGHT (W/R) and the ranking of $\mathrm{H}(\mathrm{EAD}-\mathrm{FOOT}) / \mathrm{L}(\mathrm{H} / \mathrm{L})$ above $\mathrm{H}(\mathrm{EAD}-\mathrm{FOOT}) / \mathrm{R}$ (H/R), as shown in (16) and (17).

Nick Clements (personal communication) pointed out an alternative derivational analysis for both Hindi and Preclassical Latin, which makes the same predictions with respect to preantepenultimate stress being limited to tetrasyllabic words, and which essentially mimicks the OT-account of section 5. The analysis is: (i) first construct one moraic trochee at the left word edge (mimicking high-ranked ALIGN-PRWDLEFT (W/L)), then, (ii) after final syllable extrametricality, (iii) construct moraic trochees from right-to-left, followed by (iv) End Rule Right. This is illustrated for Latin in (19). 
(19) A Rule-based Alternative I

a. ba si li cus

L $\quad$ L $\quad$ L $\quad H$

i $\quad\left(\begin{array}{ll}\mathrm{x} & .)\end{array}\right.$

ii $<\sigma>$

iii n.a

iv $(x)$

b. ma le fi ci um

L $\quad$ L $\quad$ L $\quad$ L $\quad$ H

i $\quad\left(\begin{array}{ll}\mathrm{x} & .)\end{array}\right.$

ii $<\sigma>$

iii $(\mathrm{x} \quad$.

iv $(x)$

It is important to observe that this analysis does not need the concept of Foot-Extrametricality to describe Early Classical Latin or Hindi. This, then, implies that, as far as we know, all cases of Free FootExtrametricality occur in right-ward stress systems. What is left unexplained in the derivational account is why syllable-extrametricality occurs in left-ward stress systems, but foot-extrametricality only in right-ward stress systems. It is not easy to see how, within a derivational account, one could generalize over these two types of extrametricality. The modification of the constraint NONFINALITY proposed here, on the other hand, does precisely this. It not only generalizes over syllable-extrametricality and foot-extrametricality, but, moreover, formally captures and straightforwardly explains the directional asymmetry of previous foot-extrametricality.

There is a second rule-based alternative that we have to consider. Mirco Ghini (personal communication) proposed the following straightforward analysis for Early Classical Latin. First, (20-i) the final syllable is made extrametrical, then (20-ii) moraic trochees are 
constructed, not from right-to-left, but from left-to-right. Finally, (20iii) End Rule Final produces main stress on the final foot.

(20) A Rule-based Alternative II

a. ba si li cus

L L $\quad$ L $\quad H$

$\begin{array}{llll}\text { i } & & & <\sigma> \\ \text { ii } & (x & . & \\ \text { iii } & (x & & \end{array}$

b. ma le fi ci um

L L $\quad$ L $\quad$ L $\quad H$

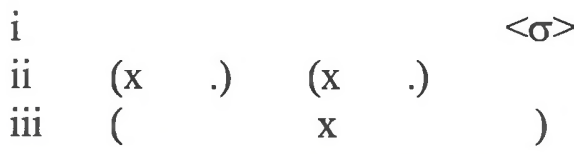

There are two word types where there is a crucial difference between this rule-based analysis and the OT-account in section 5, or, for that matter, the Rule-based Alternative I, in (19), which mimicks the OTaccount. Both in words of 6 syllables with the first 5 syllables light and in words of 5 syllables with the first syllable heavy, followed by three light syllables, preantepenultimate stress is predicted, whereas the OTaccount and Alternative I in (19) both predict antepenultimate stress. Words of the first prosodic shape (6 syllables, first 5 light) are not easy to find. One might think of cases such as restupefacio 'to make silent again' or recalefacio 'to heath again'. Words of the second prosodic shape ( 5 syllables, first heavy followed by three lights and a final syllable) are quite common. Some examples are aedificium 'building', perceleriter 'very fast' or arefacio 'to dry'. In (21), the different predictions for these words are illustrated. 
(21) Different Predictions for L L L L L $\sigma$ and H L L L $\sigma$ words

Rule-based Alternative I (19):

$\begin{array}{lllllll} & \text { L } & \text { L } & \text { L } & \text { L } & \text { L } & \\ & \text { re } & \text { stu } & \text { pe } & \text { fa } & \text { ci } & \text { o } \\ \text { i } & (\mathrm{x} & .) & & & & \\ \text { ii } & & & & & & <\sigma> \\ \text { iii } & & & & (x & .) & \\ \text { iv } & ( & & & \text { x } & & \text { ) }\end{array}$

Rule-based Alternative II (20):

$\begin{array}{llllllll} & \text { L } & \text { L } & \text { L } & \text { L } & \text { L } & & \\ & \text { re } & \text { stu } & \text { pe } & \text { fa } & \text { ci } & \text { o } & \\ & \text { i } & & & & & & <\sigma> \\ \text { ii } & \text { (x } & \text {.) } & \text { (x } & \text {.) } & & & \\ \text { iv } & ( & & \text { x } & & & \text { ) } & \end{array}$

Rule-based Alternative I (19):

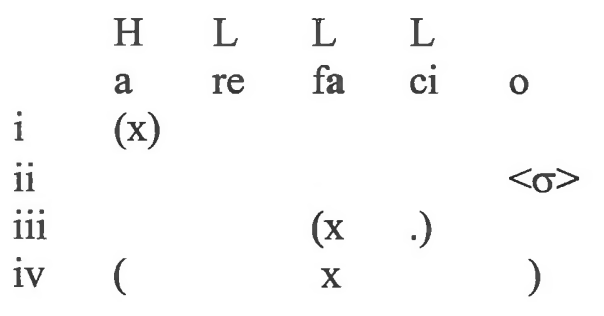

Rule-based Alternative II (20):

$\begin{array}{lllll}H & L & L & L & \\ \text { a } & \text { re } & \text { fa } & \text { ci } & 0 \\ & & & & <\sigma> \\ (x) & (x & .) & & \\ ( & x & & & \text { ) }\end{array}$


There is one crucial piece of evidence that helps us deciding between the two analyses: Lindsay (1963: 184) gives arfacio for arefacio as a possible case of syncope, which clearly points to the fact that the second syllable has to be unstressed. Although Allen (1973) remarks that in the Plautinian period in words of the type adsimiliter 'according' (first heavy, followed by three lights), the ictus, too, was preferentially on the fourth syllable from the end, Lindsay, who has edited the complete works of Plautus, is quite explicit with his "except for quadrisyllables with the first three short". In conclusion, of the two possible rule-based alternatives (19) and (20), only the one in (19) seems to be observationally adequate. The most important flaw of both analyses, as indicated above, is their impossibility to generalize over extrametricality effects.

\section{Summary}

In this paper we have modified Prince and Smolensky's NONFINALITY constraint. We have argued that the proposed simplification of NONFINALITY was needed independently of Latin in order to exclude quaternary systems. We have shown that the account provided in this paper of quaternary stress patterns (as in Early Classical Latin and Hindi) is superior to a derivational account. On the hand, it proved capable of generalizing over syllable-extrametricality and footextrametricality, relating the two to different directions of parsing, and, on the other hand, it straightforwardly accounts for the directional asymmetry of previous foot-extrametricality. Moreover, we have demonstrated that the facts of Early Classical Latin cannot be adequately described in a rule-based model, but require and OTaccount.

\section{Acknowledgements}

This paper is a revised and elaborated version of Jacobs (1999). I have profited from the comments of a number of people, of whom I would like to thank especially Nick Clements, Twan Geerts, José Hualde, and Mirco Ghini. 


\section{References}

Allen, W. S.

1973 Accent and Rhythm. Cambridge, Cambridge University Press.

Corssen, W.

1870 Uber Aussprache, Vokalismus und Betonung der lateinischen Sprache.

Fraenkel, E. Leipzig, Tubner.

1928 Iktus und Akzent im lateinischen Sprechvers. Berlin, Weidmannsche Buchhandlung.

Gupta, A.

"Hindi word stress and the Obligatory-Branching parameter" CLS 23; 134-148.

Gussenhoven, C. and H. Jacobs.

1998 Understanding Phonology. London, Arnold.

Halle, $\mathrm{M}$.

1997 “On Stress and Accent in Indo-European," Language 73, 275-313.

Hayes, B.

1995 Metrical stress theory: Principles and case studies. Chicago, Chicago University Press.

Hulst, van der $\mathrm{H}$.

1999 "Word Accent" H. van der Hulst (eds.) Word Prosodic Systems in the Languages of Europe, 3-115. Berlin, Mouton.

Jacobs, H.

1999 "Constraining Constraints: NonFinality and the Typology of FootExtrametricality" Linguistics in the Netherlands 1999, 111-120. Amsterdam/ Phildelphia, John Benjamins.

2000a "The Revenge of the Uneven Trochee: Latin Main Stress, Metrical Constituency, Stress-related Phenomena and OT." A. Lahiri (eds.) Analogy. Levelling, Markedness: Principles of Change in Phonology and Morphology, 333-352. Berlin, Mouton.

$2000 \mathrm{~b}$ The Emergence of Quantity-Sensitivity in Latin: Secondary Stress and Brevis Brevians. ms.

Kager, R.

1999 Optimality Theory: A Textbook. Cambridge, Canbridge University Press.

Lindsay, W. The Latin language. New York/London, Hafner. 2nd edition. [1894] 1963

Mester, R. A.

1994 "The Quantitative Trochee in Latin," Natural Language and Linguistic Theory 12, 1-61.

Prince, A. and P. Smolensky

1993 Optimality Theory: constraint interaction in generative grammar. Technical Report 2, Rutgers University. 
418 Haike Jacobs

Sezer, E.

1983. "On Non-Final Stress in Turkish" Journal of Turkish Studies, 5, 61-69. Thierfelder, A.

1928 "Iktierungen des Typus facilius" in E. Fraenkel. 